\title{
Long-term outcomes of liver resection for multiple hepatocellular carcinomas: Single-institution experience with 187 patients
}

\author{
Soo-Young Lee ${ }^{1}$, Chul-Soo Ahn², Young-In Yoon ${ }^{2}$, Sung-Gyu Lee ${ }^{2}$, Shin Hwang ${ }^{2}$, Ki-Hun Kim², \\ Deok-Bog Moon ${ }^{2}$, Tae-Yong $\mathrm{Ha}^{2}$, Gi-Won Song ${ }^{2}$, Dong-Hwan $\mathrm{Jung}^{2}$, and Gil-Chun Park ${ }^{2}$ \\ ${ }^{1}$ Department of Surgery, Asan Medical Center, University of Ulsan College of Medicine, \\ ${ }^{2}$ Division of Hepatobiliary Surgery and Liver Transplantation, Department of Surgery, Asan Medical Center, \\ University of Ulsan College of Medicine, Seoul, Korea
}

\begin{abstract}
Backgrounds/Aims: Surgical resection for the treatment of multiple hepatocellular carcinomas (HCCs) is controversial. This study aimed to evaluate the clinical and oncological outcomes after liver resection in patients with multiple HCCs. Methods: Clinicopathological and survival data of 187 patients who underwent curative resection for multiple HCCs between June 2004 and December 2016 at Asan Medical Center, Seoul, South Korea were retrospectively reviewed. The prognostic factors for recurrence and survival were identified using univariate and multivariate analyses. Results: Of the 187 patients, $153(81.8 \%)$ had two nodules, $23(12.3 \%)$ had three nodules, and $11(5.9 \%)$ had more than three nodules. Multiple tumors were located in the ipsilateral lobe in $163(87.2 \%)$ patients. Anatomical resection, non-anatomical resection, and both types of resections were performed in $81.3 \%, 8.0 \%$, and $10.7 \%$ patients, respectively. Recurrence occurred in $133(71.1 \%)$ patients, and the mean time to recurrence after surgery was 34.2 months. Independent risk factors for tumor recurrence in multivariate analyses were indocyanine green retention rate at $15 \mathrm{~min} \geq 15 \%$, preoperative alpha-fetoprotein level $\geq 400 \mathrm{ng} / \mathrm{ml}$, and total tumor diameter $\geq 6 \mathrm{~cm}$. The 1-, 3-, 5-, and 10 -year disease-free survival rates were $94.1 \%, 81.7 \%, 69.7 \%$, and $39.4 \%$, respectively, and the $1-, 3-, 5-$, and 10 -year survival rates were $93.5 \%, 74.2 \%, 64.9 \%$, and $38.8 \%$, respectively. Conclusions: Our experience shows that liver resection can be considered a first-line treatment option for selected patients with multiple HCCs who have well-preserved liver function. (Ann Hepatobiliary Pancreat Surg 2020;24:437-444)
\end{abstract}

Key Words: Carcinoma; Hepatocellular; Hepatectomy; Survival analysis; Multivariate analysis; Retrospective studies

\section{INTRODUCTION}

Hepatocellular carcinoma (HCC) is the most common primary neoplasm of the liver and the second leading cause of cancer-related deaths worldwide. ${ }^{1}$ Advances in diagnostic imaging and widespread implementation of surveillance programs in the high-risk population enable detection of HCC at early stages; ${ }^{2,3}$ however, some patients with HCC continue to be diagnosed with multiple tumors. ${ }^{4}$ Liver resection has been accepted as the standard treatment modality for patients who have a single lesion with well-preserved liver function. ${ }^{5}$ However, the treatment of multiple HCCs is debatable, with significant variation in the different modalities of treatment across dif- ferent hepatobiliary institutions.

The choice of treatment for patients with multiple HCCs is based on not only the stage of the tumor but also the degree of liver dysfunction. Although liver transplantation (LT) is considered the optimal treatment for patients with multiple HCCs if the tumors are small and limited in number, ${ }^{6}$ its implementation is limited by the availability of donor organs, tumor progression while on the wait list, and technical demand.

With the advances in surgical techniques and perioperative management in recent times, aggressive surgical resection for multiple HCC has been proposed for patients in whom all the tumors can be completely excised and adequate liver function can be preserved postoperatively.

Received: April 6, 2020; Revised: October 14, 2020; Accepted: October 15, 2020

Corresponding author: Chul-Soo Ahn

Division of Hepatobiliary Surgery and Liver Transplantation, Department of Surgery, Asan Medical Center, University of Ulsan College of Medicine, 88 Olympic-ro 43-gil, Songpa-gu, Seoul 05505, Korea

Tel: +82-2-3010-3942, Fax: +82-2-3010-6701, E-mail: ahncs@amc.seoul.kr

Copyright (C) 2020 by The Korean Association of Hepato-Biliary-Pancreatic Surgery

This is an Open Access article distributed under the terms of the Creative Commons Attribution Non-Commercial License (http://creativecommons.org/ licenses/by-nc/4.0) which permits unrestricted non-commercial use, distribution, and reproduction in any medium, provided the original work is properly cited. Annals of Hepato-Biliary-Pancreatic Surgery - pISSN: 2508-5778 - elSSN: 2508-5859 
Furthermore, several previous studies have suggested that liver resection can provide survival benefits in patients with multiple HCCs either within or beyond the Milan criteria. $^{7-11}$ However, the role of liver resection for multiple HCCs is controversial as resection can be associated with potentially higher intraoperative risks, increased recurrence, and worse long-term survival. This study aimed to evaluate the clinical and oncological outcomes and determine the prognostic factors for recurrence and survival after liver resection in patients with multiple HCC.

\section{MATERIALS AND METHODS}

The medical records of patients who underwent curative resection for multiple HCCs from June 2004 to December 2016 at the Asan Medical Center, Seoul, South Korea were retrospectively reviewed. Patients who had undergone liver resection for HCC at other hospitals and those who underwent salvage liver transplantation for recurrence after resection for multiple HCCs were excluded. Finally, 187 patients with multiple HCCs were included in this study. Multiple HCCs were diagnosed when there were two or more tumors. The diagnosis of HCC and the number of HCCs were confirmed by histopathological examination of the surgical specimens.

\section{Preoperative evaluation}

Preoperative diagnosis of multiple HCCs was based on preoperative imaging studies including dynamic computed tomography (CT) and magnetic resonance image (MRI) or a combination of imaging findings and elevated serum alpha-fetoprotein (AFP) and prothrombin induced by vitamin $\mathrm{K}$ absence II (PIVKA-II) levels. Liver function was assessed in detail using liver biochemistry test results, coagulation profile, indocyanine green retention rate at 15 min (ICGR15), and Child-Pugh classification. The presence of portal hypertension (esophageal varix, noticeable collaterals, and splenomegaly with thrombocytopenia) was also assessed. Based on these laboratory and radiologic examinations, the extent of resection was determined.

\section{Postoperative follow-up}

Patients were followed up using abdominal contrast-enhanced CT or MRI and chest X-ray every 2-3 months during the first year after resection, every 4 months during the second year, and every 6 months subsequently. Serum AFP levels were measured at the same intervals.

The diagnosis of intrahepatic recurrence was established on imaging if the tumor showed the typical enhancement characteristics. The line of treatment followed for recurrent HCC was essentially the same as that for primary HCC. Patients with extrahepatic recurrence were managed with all available locoregional treatment modalities. Patients with unsatisfactory responses to locoregional treatments were finally treated with systemic chemotherapy.

\section{Ethical considerations}

This study protocol was reviewed and approved by the institutional review board of the Asan Medical Center (approval number 2020-1502) at the University of Ulsan College of Medicine in Seoul, Korea. The requirement for informed consent was waived because of the retrospective nature of the study.

\section{Statistical analysis}

Data are expressed as mean \pm standard deviation. Discrete variables are presented as totals and percentages. The recurrence-free survival (RFS) and overall survival (OS) were calculated using the Kaplan-Meier method. Variables that showed statistical significance $(p<0.05)$ in the univariate analysis were subsequently included in a multivariate analysis using Cox proportional hazards regression models. Statistical significance was set at $p<$ 0.05. All statistical analyses were performed using SPSS version 21.0 (SPSS Inc., Chicago, IL, USA) for Windows.

\section{RESULTS}

\section{Clinicopathological features of all patients}

The clinical characteristics of the 187 patients with multiple HCCs are shown in Table 1. Of the 187 patients, $158(84.5 \%)$ were male. Of all patients, $158(84.5 \%)$ and $15(8.0 \%)$ patients had associated hepatitis B and $\mathrm{C}$ virus infection, respectively. Further, 97.9\% patients had relatively good liver function with Child-Pugh class A. Liver cirrhosis was present in $147(75.9 \%)$ patients, confirmed on histological examination after surgery. The preopera-

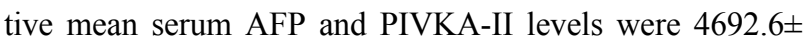


Table 1. Demographics characteristics of the patients

\begin{tabular}{|c|c|}
\hline Variables & Total $(n=187)$ \\
\hline Sex, M:F & 158:29 \\
\hline Age, mean $( \pm \mathrm{SD}$, year $)$ & $58.8( \pm 9.71)$ \\
\hline \multicolumn{2}{|l|}{ Liver disease, $\mathrm{n}(\%)$} \\
\hline $\mathrm{HBV}$ & $158(84.5)$ \\
\hline $\mathrm{HCV}$ & $15(8.0)$ \\
\hline $\mathrm{HBV}$ and $\mathrm{HCV}$ & $1(0.5)$ \\
\hline Others & $5(2.7)$ \\
\hline \multicolumn{2}{|l|}{ Comorbid disease, $\mathrm{n}(\%)$} \\
\hline Cardiac disease & $58(31.0)$ \\
\hline Pulmonary disease & $1(0.5)$ \\
\hline Renal disease & $1(0.5)$ \\
\hline Diabetes mellitus & $42(22.5)$ \\
\hline Others & $1(0.5)$ \\
\hline ASA score $\mathrm{I} / \mathrm{II} / \mathrm{III}$ & $3 / 180 / 4$ \\
\hline CTP score A/B & $183 / 4$ \\
\hline \multicolumn{2}{|l|}{ Preoperative blood tests, mean $( \pm \mathrm{SD})$} \\
\hline Hemoglobin $(\mathrm{g} / \mathrm{dl})$ & $13.5( \pm 1.53)$ \\
\hline Total bilirubin $(\mu \mathrm{mol} / \mathrm{L})$ & $0.7( \pm 0.27)$ \\
\hline AST (IU/L) & $41.3( \pm 28.29)$ \\
\hline ALT (IU/L) & $37.8( \pm 27.25)$ \\
\hline PT (INR) & $1.1( \pm 0.08)$ \\
\hline Creatinine (mg/dl) & $0.9( \pm 0.85)$ \\
\hline Albumin $(\mathrm{g} / \mathrm{dl})$ & $3.6( \pm 0.39)$ \\
\hline Platelet count $\left(\times 10^{3} / \mu \mathrm{l}\right)$ & $156.8( \pm 63.26)$ \\
\hline $\mathrm{AFP}(\mathrm{ng} / \mathrm{ml})$ & $4692.6( \pm 29256.36)$ \\
\hline PIVKA-II (mAU/ml) & $633.1( \pm 2735.05)$ \\
\hline ICG-r15 (\%) & $13.9( \pm 6.66)$ \\
\hline \multicolumn{2}{|l|}{ History of HCC treatment } \\
\hline TACE & $65(34.8)$ \\
\hline RFA & $19(10.2)$ \\
\hline Preoperative portal vein embolization & $29(15.5)$ \\
\hline BCLC stage $\mathrm{A} / \mathrm{B} / \mathrm{C}$ & $20 / 162 / 5$ \\
\hline
\end{tabular}

$\mathrm{SD}$, standard deviation; HBV, hepatitis B virus; HCV, hepatitis $\mathrm{C}$ virus; ASA, American society of anesthesiologists; CTP, child-turcotte-pugh; AST, aspartate transaminase; ALT, alanine transaminase; PT, prothrombin time; AFP, alpha-fetoprotein; PIVKA-II, prothrombin induced by vitamin $\mathrm{K}$ absence II; ICG, indocyanine green; HCC, hepatocellular carcinoma; TACE, transarterial chemoembolization; RFA, radiofrequency ablation; BCLC, Barcelona Clinic Liver Cancer

$29256.36 \mathrm{ng} / \mathrm{ml}$ and $633.1 \pm 2735.05 \mathrm{mAU} / \mathrm{ml}$, respectively. Of the 187 patients, $84(45.0 \%)$ received preoperative treatment -65 were treated with transarterial chemoembolization (TACE) and 19 were treated with radiofrequency ablation (RFA).

The characteristics of HCC are summarized in Table 2. Of the 187 patients, $153(81.8 \%)$ had two nodules, 23 $(12.3 \%)$ had three nodules, and 11 (5.9\%) had more than three nodules. Multiple tumors were located in the ipsilateral lobe in $163(87.2 \%)$ patients. On histopathological
Table 2. Tumor characteristics

\begin{tabular}{lc}
\hline \multicolumn{1}{c}{ Characteristics } & Total $(\mathrm{n}=187)$ \\
\hline Tumor distribution, n (\%) & \\
Ipsilateral lobe $163(87.2)$ & $161(86.1)$ \\
Right lobe & $50(26.7)$ \\
Left lobe & $24(12.8)$ \\
Bilateral lobe & \\
Pathological characteristics & $142(75.9)$ \\
Liver cirrhosis, n $(\%)$ & $153 / 23 / 11$ \\
Number of tumors, n $(\%)$ 2/3/more & $(81.8 / 12.3)$ \\
& $4.1( \pm 3.11)$ \\
Size of the largest tumor, cm $( \pm$ SD) & $6.1( \pm 3.82)$ \\
Total tumor diameter, cm $( \pm$ SD) & $13.1( \pm 15.16)$ \\
Tumor-free margin, mm $( \pm$ SD) & $42(22.5)$ \\
Lymphovascular invasion, n $(\%)$ & $16(8.5)$ \\
Satellite nodule, n $(\%)$ & $9(0.5)$ \\
Bile duct invasion, n $(\%)$ & $19(10.2)$ \\
Portal vein invasion, $\mathrm{n}(\%)$ & $20(10.7)$ \\
Glisson capsule invasion, n $(\%)$ & $58 / 114$ \\
Edmondson-Steiner grade, n $(\%)$ I, II/III, IV & $(30.9 / 61.0)$ \\
\hline
\end{tabular}

$\mathrm{SD}$, standard deviation

examination, the mean largest tumor size was $4.1 \mathrm{~cm}$, and the total tumor diameter was $6.1 \pm 3.82 \mathrm{~cm}$. The rates of microvascular and macrovascular invasion were $22.5 \%$ and $10.2 \%$, respectively. Further, 114 (61.0\%) patients had Edmondson-Steiner grade III or IV cancer.

The extent of resection in all patients is summarized in Table 3. Anatomical resection, non-anatomical resection, and both types of resections were performed in $81.3 \%, 8.0 \%$, and $10.7 \%$ patients, respectively. Tumor-free resection margin was obtained in all patients. Tumor thrombectomy from the portal vein and combined resection of the adjacent organs was performed in 4 patients $(2.1 \%)$ and 9 patients (4.8\%), respectively.

\section{Tumor recurrence}

Recurrence was seen in $133(71.1 \%)$ patients during the follow-up, and the mean time to recurrence after surgery was 34.2 months. Of these, 109 patients had only intrahepatic recurrence, 14 had only extrahepatic recurrence, and 10 had both intrahepatic and extrahepatic recurrence. The most common treatment modalities for the recurrence of HCC were TACE $(n=96,72.2 \%)$ and RFA $(n=18$, $13.5 \%$ ) (Table 4).

Overall, the 1-, 3-, 5-, and 10-year disease-free survival (DFS) rates were $94.1 \%, 81.7 \%, 69.7 \%$, and $39.4 \%$, re- 
Table 3. Type of resection

\begin{tabular}{|c|c|}
\hline Types & Total $(n=187)$ \\
\hline Open/laparoscopic approach, n (\%) & $185 / 2(98.9 / 1.1)$ \\
\hline Anatomical/non anatomical resection/Both, n (\%) & $152 / 15 / 20(81.3 / 8.0 / 10.7)$ \\
\hline \multicolumn{2}{|l|}{ Type of resection, n (\%) } \\
\hline Right hepatectomy & $53(27.9)$ \\
\hline Right hepatectomy+wedge resection & $5(2.7)$ \\
\hline Right anterior sectionectomy & $27(14.4)$ \\
\hline Right anterior sectionectomy+wedge & $2(1.1)$ \\
\hline \multicolumn{2}{|l|}{ Resection } \\
\hline Right posterior sectionectomy & $28(15.0)$ \\
\hline Right posterior sectionectomy + wedge & $5(2.7)$ \\
\hline \multicolumn{2}{|l|}{ Resection } \\
\hline Right trisectionectomy & $1(0.5)$ \\
\hline Right trisectionectomy+wedge resection & $1(0.5)$ \\
\hline Central bisectionectomy & $3(1.6)$ \\
\hline Left medial sectionectomy & $1(0.5)$ \\
\hline Left medial segmenctectomy $+\mathrm{S} 3$ & $1(0.5)$ \\
\hline \multicolumn{2}{|l|}{ Segmentectomy } \\
\hline Left medial segmentectomy+wedge & $1(0.5)$ \\
\hline \multicolumn{2}{|l|}{ Resection } \\
\hline Extended left hepatectomy & $1(0.5)$ \\
\hline Left hepatectomy & $11(5.8)$ \\
\hline Left hepatectomy+wedge resection & $4(2.1)$ \\
\hline Left lateral sectionectomy & $11(5.8)$ \\
\hline Left lateral sectionectomy+wedge resection & $2(1.1)$ \\
\hline Monosectionectomy & $14(7.5)$ \\
\hline S5, 6 segmentectomy & $1(0.5)$ \\
\hline Wedge resection & $15(8.0)$ \\
\hline Tumor thrombectomy, portal vein, $\mathrm{n}(\%)$ & $4(2.1)$ \\
\hline Combined resection of adjacent organs & $9(4.8)$ \\
\hline
\end{tabular}

Table 4. Recurrence pattern and the treatment for recurrence

\begin{tabular}{lc}
\hline \multicolumn{1}{c}{ Pattern and treatment } & $\begin{array}{c}\text { Number of } \\
\text { recurrences }(\mathrm{n}=133)\end{array}$ \\
\hline $\begin{array}{c}\text { Time to recurrence after surgery, } \\
\text { (mean, months) }\end{array}$ & 34.2 \\
Site of recurrences: & $109 / 14 / 10$ \\
Intrahepatic/extrahepatic, n (\%) & $(82.0 / 10.5 / 7.5)$ \\
Number of intrahepatic recurrences: & $70 / 49$ \\
Single/multiple, n $(\%)$ & $(37.4 / 26.2)$ \\
Treatment for recurrence & \\
TACE & $96(72.2)$ \\
RFA & $18(13.5)$ \\
RT & $9(6.8)$ \\
Re-resection & $10(7.5)$ \\
Chemotherapy & $10(7.5)$ \\
\hline
\end{tabular}

TACE, transarterial chemoembolization; RFA, radiofrequency ablation; RT, radiative therapy

spectively (Fig. 1A). Univariate analysis showed that ICGR15 $\geq 15 \%$, preoperative AFP level $\geq 400 \mathrm{ng} / \mathrm{ml}$, number of tumors $\geq 3$, size of the largest tumor $\geq 3 \mathrm{~cm}$, total tumor diameter $\geq 6 \mathrm{~cm}$, and presence of lymphovascular invasion were predictors of recurrence. Multivariate analysis showed that ICGR $15 \geq 15 \%$, preoperative alpha-fetoprotein level $\geq 400 \mathrm{ng} / \mathrm{ml}$, and total tumor diameter $\geq 6 \mathrm{~cm}$ ) were predictors of recurrence (Table 5).

\section{Overall survival}

The cumulative OS rates for all patients at 1-, 3-, 5-, and 10 -years were $93.5 \%, 74.2 \%, 64.9 \%$, and $38.8 \%$, respectively (Fig. 1B).

Univariate analysis revealed that size of the largest tumor $\geq 3 \mathrm{~cm}$ ) and total tumor diameter $\geq 6 \mathrm{~cm}$ were predictors of survival. On multivariate analysis, total tumor diameter $\geq 6 \mathrm{~cm}$ was the only significant predictor of survival (Table 6). 

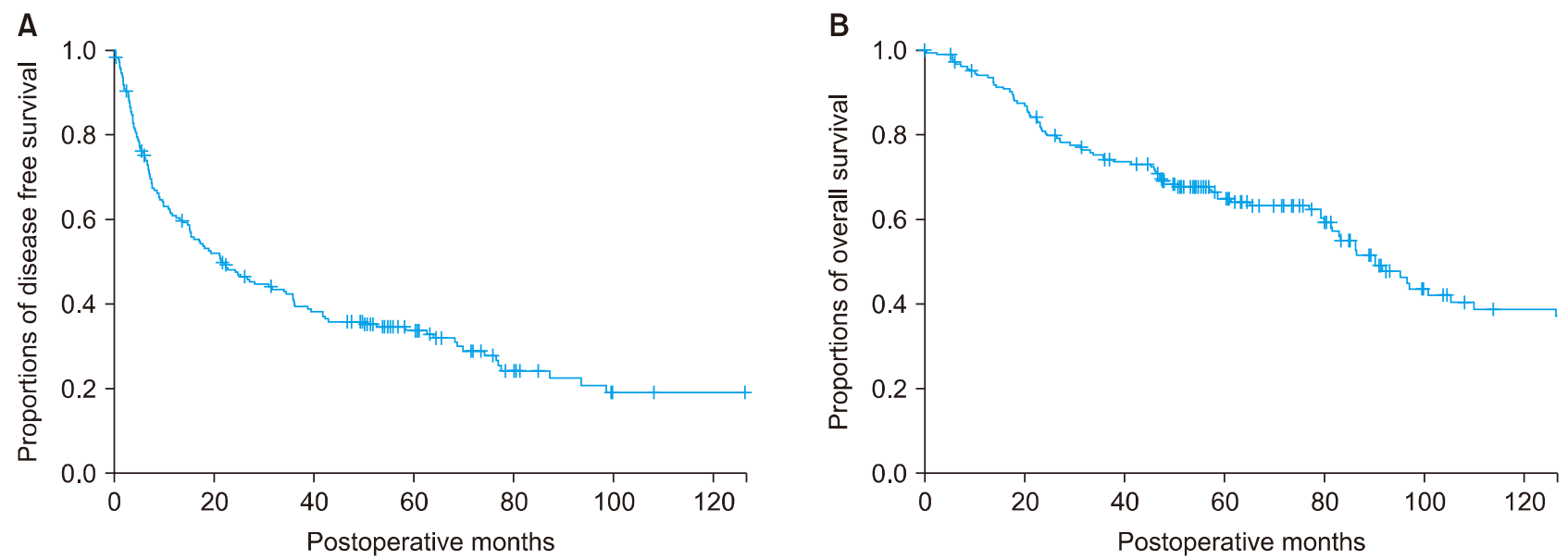

Fig. 1. (A) Disease-free survival rates and (B) overall survival rates and in patients who underwent liver resection for multiple HCC.

Table 5. Univariate and multivariate analysis of risk factors for recurrence

\begin{tabular}{|c|c|c|c|c|c|c|c|c|}
\hline \multirow[b]{2}{*}{ Varables } & \multicolumn{4}{|c|}{ Univariate } & \multicolumn{4}{|c|}{ Multivariate } \\
\hline & $\begin{array}{c}\text { Hazard } \\
\text { ratio }\end{array}$ & $95 \%$ & $\mathrm{CI}$ & $p$ & $\begin{array}{c}\text { Hazard } \\
\text { ratio }\end{array}$ & $95 \%$ & $\mathrm{CI}$ & $p$ \\
\hline Age $\geq 70$ years & 0.822 & 0.480 & 1.408 & 0.475 & & & & \\
\hline Sex, male & 0.942 & 0.596 & 1.490 & 0.798 & & & & \\
\hline Cirrhosis, $(\mathrm{P})^{*}$ & 1.263 & 0.827 & 1.930 & 0.280 & & & & \\
\hline Serum albumin $<4 \mathrm{~g} / \mathrm{dl}$ & 1.229 & 0.737 & 2.049 & 0.429 & & & & \\
\hline Serum total bilirubin $\geq 1 \mathrm{mg} / \mathrm{dl}$ & 1.243 & 0.821 & 1.880 & 0.304 & & & & \\
\hline ICGR $15^{\dagger} \geq 15 \%$ & 1.510 & 1.067 & 2.138 & 0.020 & 1.549 & 1.087 & 2.207 & 0.015 \\
\hline Prothrombin activity $\geq 85 \%$ & 1.027 & 0.701 & 1.504 & 0.891 & & & & \\
\hline Platelet count $\geq 15 \times 10^{4} / \mathrm{mm}^{3}$ & 0.935 & 0.662 & 1.319 & 0.701 & & & & \\
\hline Preoperative AFP $\geq 400 \mathrm{ng} / \mathrm{ml}$ & 1.618 & 1.029 & 2.544 & 0.037 & 1.685 & 1.061 & 2.675 & 0.027 \\
\hline Number of tumors $\geq 3(\mathrm{P})^{*}$ & 1.672 & 1.099 & 2.542 & 0.016 & & & & \\
\hline Satellite nodule & 1.602 & 0.902 & 2.844 & 0.108 & & & & \\
\hline Tumor distribution, bilateral lobe & 1.245 & 0.765 & 2.025 & 0.378 & & & & \\
\hline Size of the largest tumor $\geq 3 \mathrm{~cm}(\mathrm{P})^{*}$ & 2.008 & 1.400 & 2.880 & 0.000 & & & & \\
\hline Total tumor diameter $\geq 6 \mathrm{~cm}(\mathrm{P})^{*}$ & 2.292 & 1.619 & 3.246 & 0.000 & 1.803 & 1.130 & 2.879 & 0.013 \\
\hline Lymphovascular invasion $(\mathrm{P})^{*}$ & 1.626 & 1.094 & 2.419 & 0.016 & & & & \\
\hline Non anatomical resection & 1.458 & 0.963 & 2.208 & 0.075 & & & & \\
\hline
\end{tabular}

*Identified after postoperative pathological examination; ${ }^{\dagger}$ Indocyanine green retention rate at $15 \mathrm{~min}$ CI, confidence interval; AFP, alpha-fetoprotein

\section{DISCUSSION}

Our study showed that surgical resection can provide acceptable OS for patients with multiple HCCs. In the present study, the 1-, 3-, 5-, and 10-year DFS rates were $94.1 \%, 81.7 \%, 69.7 \%$, and $39.4 \% \%$, respectively, and the 1-, 3-, 5-, and 10-year OS rates were 93.5\%, 74.2\%, $64.9 \%$, and $38.8 \%$, respectively. Both the survival rates were promising. This was owing to early detection of recurrence and aggressive treatment for both intrahepatic and extrahepatic recurrences with close follow-up and surveillance imaging examination.

The management of HCC is complicated because of its heterogenous biological behavior and association with chronic liver disease. ${ }^{12}$ In South Korea, HCC is the second leading cause of cancer mortality and it is the fifth most common newly diagnosed cancer. ${ }^{13}$ The choice of treatment in patients with HCC depends on not only tumor staging but also careful evaluation of liver function and physical status. For the treatment of multiple HCCs, surgi- 
Table 6. Univariate and multivariate analysis of overall survival in patients with multiple hepatocellular carcinomas

\begin{tabular}{|c|c|c|c|c|c|c|c|c|}
\hline \multirow[b]{2}{*}{ Variables } & \multicolumn{4}{|c|}{ Univariate } & \multicolumn{4}{|c|}{ Multivariate } \\
\hline & $\begin{array}{c}\text { Hazard } \\
\text { ratio }\end{array}$ & $95 \%$ & CI & $p$ & $\begin{array}{l}\text { Hazard } \\
\text { ratio }\end{array}$ & $95 \%$ & CI & $p$ \\
\hline Age $\geq 70$ years & 0.493 & 0.117 & 2.076 & 0.335 & & & & \\
\hline Sex, male & 0.838 & 0.341 & 2.060 & 0.700 & & & & \\
\hline Cirrhosis, $(\mathrm{P})^{*}$ & 1.191 & 0.484 & 2.926 & 0.704 & & & & \\
\hline Serum albumin $<4 \mathrm{~g} / \mathrm{dl}$ & 0.712 & 0.289 & 1.752 & 0.459 & & & & \\
\hline Serum total bilirubin $\geq 1 \mathrm{mg} / \mathrm{dl}$ & 0.700 & 0.243 & 2.015 & 0.509 & & & & \\
\hline $\operatorname{ICGR}_{15}{ }^{\dagger} \geq 15 \%$ & 2.095 & 0.993 & 4.420 & 0.052 & & & & \\
\hline Prothrombin activity $\geq 85 \%$ & 0.532 & 0.253 & 1.116 & 0.095 & & & & \\
\hline Platelet count $\geq 15 \times 10^{4} / \mathrm{mm}^{3}$ & 1.052 & 0.507 & 2.184 & 0.891 & & & & \\
\hline Preoperative AFP $\geq 400$ & 1.236 & 0.471 & 3.242 & 0.667 & & & & \\
\hline Number of tumors $\geq 3(\mathrm{P})^{*}$ & 1.199 & 0.488 & 2.948 & 0.692 & & & & \\
\hline Satellite nodule & 2.091 & 0.727 & 6.018 & 0.171 & & & & \\
\hline Tumor distribution, bilateral lobe & 0.771 & 0.233 & 2.549 & 0.670 & & & & \\
\hline Size of the largest tumor $\geq 3 \mathrm{~cm}(\mathrm{P})^{*}$ & 2.278 & 1.009 & 5.145 & 0.048 & & & & \\
\hline Total tumor diameter $\geq 6 \mathrm{~cm}( \pm \mathrm{SD})(\mathrm{P})^{*}$ & 2.431 & 1.168 & 5.058 & 0.017 & 2.476 & 1.172 & 5.231 & 0.018 \\
\hline Lymphovascular invasion $(\mathrm{P})^{*}$ & 1.411 & 0.602 & 3.309 & 0.428 & & & & \\
\hline Non anatomical resection & 1.216 & 0.519 & 2.851 & 0.653 & & & & \\
\hline
\end{tabular}

*Identified after postoperative pathological examination; ${ }^{\dagger}$ Indocyanine green retention rate at $15 \mathrm{~min}$ CI, confidence interval; AFP, alpha-fetoprotein

cal and nonsurgical modalities have been used, but the treatment strategies are controversial. ${ }^{14}$ LT has been generally considered the treatment of choice for small and limited multiple HCCs as it can resolve the corresponding underlying liver cirrhosis and HCC. ${ }^{6,15}$ Even in patients with HCC beyond the Milan criteria, LT has been performed alone or in combination with a nonsurgical modality, such as TACE, RFA, and percutaneous ethanol injection, to control the tumor as much as possible. However, there are many controversies regarding LT in patients with HCC, such as selection of patients considering the organ shortage, tumor progression while on the wait list, use of living donors, and choice of immunosuppression or adjuvant therapies. ${ }^{16}$

In addition to transplantation, surgical resection and TACE are the two most widely used treatments for multiple HCCs. TACE is the most commonly used and is considered the standard palliative treatment for patients with multiple HCCs. ${ }^{5}$ TACE can induce extensive necrosis in $>50 \%$ patients $^{17}$ and improve their survival. ${ }^{18,19}$ However, several studies have suggested that palliative TACE results in a high incidence of viable residual tumor, even after repeated TACE, ${ }^{20,21}$ and that the poor response in avascular and/or large tumors restricts its use for treating HCCs. Moreover, in recent retrospective cohort studies, resection provided better survival than TACE, even in patients with multiple HCCs in various stages. ${ }^{4,9,10,22}$ Therefore, liver resection should be included as a treatment option for multiple HCCs in patients who have well-preserved hepatic function.

The indications for surgery in patients with multiple HCC have not been established thus far. The predictors of survival for multiple HCCs found in our study were similar to those reported for HCCs in previous studies. ${ }^{4,23}$ In our study, multivariate analysis identified that total tumor diameter $\geq 6 \mathrm{~cm}$ was an independent prognostic factor for both DFS and OS. These results on the prognostic factor in patients with multiple HCCs can help in patient selection for liver resection.

There are a few limitations in our study. First, this study was retrospective in nature, and there might be some selection bias in the choice of treatment. Second, comparison with alternative treatment modalities was not performed. To confirm the efficacy of resection for multiple HCCs, its superiority over non-surgical treatment should be proven. Third, our results are mainly based on the data of patients with two HCCs. Further randomized, prospective studies including comparison with alternative treatment modalities and with a large number of patients are necessary to confirm the therapeutic role of liver re- 
section in the treatment of patients with multiple HCCs.

In conclusion, on the basis of our experience of liver resection for multiple HCCs, we suggest that surgical resection could be an important strategy to improve longterm outcomes. However, careful selection of candidates for surgery, meticulous surgical techniques, and early detection and aggressive treatment for recurrence is necessary. In addition, given the complexity of HCC and the availability of several potentially useful treatment modalities, the treatment of patients with multiple HCCs associated with chronic liver disease should be discussed with a multidisciplinary team, including hepatologists, surgeons, radiologists, and oncologists.

\section{CONFLICT OF INTEREST}

There is no conflict of interest.

\section{ORCID}

Soo-Young Lee: https://orcid.org/0000-0002-3916-848X

Chul-Soo Ahn: https://orcid.org/0000-0002-3844-3646

Young-In Yoon: https://orcid.org/0000-0002-9308-0366

Sung-Gyu Lee: https://orcid.org/0000-0001-9161-3491

Shin Hwang: https://orcid.org/0000-0002-9045-2531

Ki-Hun Kim: https://orcid.org/0000-0002-4016-0995

Deok-Bog Moon: https://orcid.org/0000-0002-8209-3540

Tae-Yong Ha: https://orcid.org/0000-0001-9932-0212

Gi-Won Song: https://orcid.org/0000-0002-4235-0434

Dong-Hwan Jung: https://orcid.org/0000-0001-5984-023X

Gil-Chun Park: https://orcid.org/0000-0003-1631-3258

\section{AUTHOR CONTRIBUTIONS}

Conceptualization: CSA. Data curation: SYL, YIY, SGL, SH, KHK, DBM, TYH, GWS, DHJ, GCP. Formal analysis: SYL, CSA, YIY, TYH, GWS, DHJ, KHK, DBM, GCP. Methodology: SYL, YIY. Writing - original draft: SYL, CSA. Writing - review \& editing: SYL, CSA, YIY.

\section{REFERENCES}

1. Ferlay J, Soerjomataram I, Dikshit R, Eser S, Mathers C, Rebelo $\mathrm{M}$, et al. Cancer incidence and mortality worldwide: sources, methods and major patterns in GLOBOCAN 2012. Int J Cancer 2015;136:E359-E386.

2. El-Serag HB, Mason AC. Rising incidence of hepatocellular carcinoma in the United States. N Engl J Med 1999;340:745-750.

3. Bosch FX, Ribes J, Díaz M, Cléries R. Primary liver cancer: worldwide incidence and trends. Gastroenterology 2004;127(5 Suppl 1):S5-S16.

4. Ho MC, Huang GT, Tsang YM, Lee PH, Chen DS, Sheu JC, et al. Liver resection improves the survival of patients with multiple hepatocellular carcinomas. Ann Surg Oncol 2009;16:848855 .

5. Bruix J, Sherman M; Practice Guidelines Committee, American Association for the Study of Liver Diseases. Management of hepatocellular carcinoma. Hepatology 2005;42:1208-1236.

6. Yao FY, Ferrell L, Bass NM, Watson JJ, Bacchetti P, Venook A, et al. Liver transplantation for hepatocellular carcinoma: expansion of the tumor size limits does not adversely impact survival. Hepatology 2001;33:1394-1403.

7. Ishizawa $\mathrm{T}$, Hasegawa K, Aoki T, Takahashi M, Inoue $\mathrm{Y}$, Sano $\mathrm{K}$, et al. Neither multiple tumors nor portal hypertension are surgical contraindications for hepatocellular carcinoma. Gastroenterology 2008;134:1908-1916.

8. Torzilli G, Donadon M, Marconi M, Palmisano A, Del Fabbro D, Spinelli A, et al. Hepatectomy for stage B and stage C hepatocellular carcinoma in the Barcelona Clinic Liver Cancer classification: results of a prospective analysis. Arch Surg 2008;143: 1082-1090.

9. Lin CT, Hsu KF, Chen TW, Yu JC, Chan DC, Yu CY, et al. Comparing hepatic resection and transarterial chemoembolization for Barcelona Clinic Liver Cancer (BCLC) stage B hepatocellular carcinoma: change for treatment of choice? World J Surg 2010;34:2155-2161.

10. Ho CM, Lee PH, Chen CL, Ho MC, Wu YM, Hu RH. Long-term outcomes after resection versus transplantation for hepatocellular carcinoma within UCSF criteria. Ann Surg Oncol 2012;19:826-833.

11. Ramacciato G, Mercantini P, Petrucciani N, Ravaioli M, Cucchetti A, Del Gaudio M, et al. Does surgical resection have a role in the treatment of large or multinodular hepatocellular carcinoma? Am Surg 2010;76:1189-1197.

12. Guo H, Wu T, Lu Q, Li M, Guo JY, Shen Y, et al. Surgical resection improves long-term survival of patients with hepatocellular carcinoma across different Barcelona Clinic Liver Cancer stages. Cancer Manag Res 2018;10:361-369.

13. Jung KW, Park S, Won YJ, Kong HJ, Lee JY, Park EC, et al. Prediction of cancer incidence and mortality in Korea, 2011. Cancer Res Treat 2011;43:12-18.

14. Korean Liver Cancer Association (KLCA); National Cancer Center (NCC), Goyang, Korea. 2018 Korean Liver Cancer Association-National Cancer Center Korea Practice Guidelines for the management of hepatocellular carcinoma. Korean $\mathrm{J}$ Radiol 2019;20:1042-1113.

15. Mazzaferro V, Regalia E, Doci R, Andreola S, Pulvirenti A, Bozzetti F, et al. Liver transplantation for the treatment of small hepatocellular carcinomas in patients with cirrhosis. N Engl J Med 1996;334:693-699.

16. Clavien PA, Lesurtel M, Bossuyt PM, Gores GJ, Langer B, Perrier A. Recommendations for liver transplantation for hepatocellular carcinoma: an international consensus conference report. Lancet Oncol 2012;13:e11-e22.

17. Llovet JM, Bruix J. Systematic review of randomized trials for unresectable hepatocellular carcinoma: chemoembolization improves survival. Hepatology 2003;37:429-442.

18. Lo CM, Ngan H, Tso WK, Liu CL, Lam CM, Poon RT, et al. 
Randomized controlled trial of transarterial lipiodol chemoembolization for unresectable hepatocellular carcinoma. Hepatology 2002;35:1164-1171

19. Llovet JM, Real MI, Montaña X, Planas R, Coll S, Aponte J, et al. Arterial embolisation or chemoembolisation versus symptomatic treatment in patients with unresectable hepatocellular carcinoma: a randomised controlled trial. Lancet 2002;359:1734-1739.

20. Poon RT, Ngan H, Lo CM, Liu CL, Fan ST, Wong J. Transarterial chemoembolization for inoperable hepatocellular carcinoma and postresection intrahepatic recurrence. J Surg Oncol 2000;73:109-114.
21. Trevisani F, De Notariis S, Rossi C, Bernardi M. Randomized control trials on chemoembolization for hepatocellular carcinoma: is there room for new studies? J Clin Gastroenterol 2001; 32:383-389.

22. Ng KK, Vauthey JN, Pawlik TM, Lauwers GY, Regimbeau JM, Belghiti $\mathrm{J}$, et al. Is hepatic resection for large or multinodular hepatocellular carcinoma justified? Results from a multi-institutional database. Ann Surg Oncol 2005;12:364-373.

23. Fukami Y, Kaneoka Y, Maeda A, Kumada T, Tanaka J, Akita $\mathrm{T}$, et al. Liver resection for multiple hepatocellular carcinomas: a Japanese nationwide survey. Ann Surg 2020;272:145-154. 